\title{
Social impacts of health care reforms in Russia
}

\author{
Tatyana Tagaeva ${ }^{1, *}$ and Lidiya Kazantseva ${ }^{1}$ \\ ${ }^{1}$ Institute of Economics and Industrial Engineering, Siberian Branch of Russian Academy of Sciences, \\ Novosibirsk State University, Novosibirsk, 2 Pirogova Street, Novosibirsk, 630090, Russia
}

\begin{abstract}
The article considers the stages of healthcare sector reforms in Russia and the impact of this process on public health as the main indicator of the social state. A definition of public health is given; the scientific significance and relevance of the research are justified. The works of foreign and domestic authors, their approaches to the study of factors affecting public health are analysed. The analysis of the state of public health in $80 \mathrm{~s}-90 \mathrm{~s}$ of the last century during the political and economic crisis is made; the transition process from the so-called "budget-funded" financing model to the "insurance" one is described. Based on statistics and expert assessments, as well as international confrontations, conclusions are drawn about the multi-year underfunding of the healthcare sector, primarily from the state budget. A new stage of reforms is analysed: since 2014, the Russian government has begun the so-called "optimization" of healthcare. Its goals, results, feedbacks from doctors and patients are stated. They show the new reform is a negative process for health system. The blunders of health care reform have been sharply marked with the beginning of the pandemic of coronavirus infection. The facts of the selfsacrificing work of the doctors and nursing personnel during the pandemic period, the measures of the Government and the society to support medical workers were described.
\end{abstract}

\section{Introduction}

The main social indicator influenced by the reform of the health system in Russia is public health. Public health is a set of characteristics of the population health of the state as a single functioning organism based on the analysis of medical and demographic indicators. The state of public health has a significant impact on the economic system as a whole. The problem of public health deterioration is very relevant and requires a special attention, since health directly or indirectly affects all spheres of human life.

Reduction of doctors and nursing personnel, the increase of a personal load on district doctors, the extermination and enlargement of medical organizations, the increase of a waiting time for specialists admission and the numerous denial of ambulance services, low rates of doctors salaries growth, the commercialization of health care, the inaccessibility of qualified care for most citizens of the Russian Federation due to a low income. These are the main results of "optimization" which has caused the distrust of medical institutions and

\footnotetext{
* Corresponding author: $\mathrm{kk@ieie.nsc.ru}$
} 
dissatisfaction with the government. The positive moment of "optimization" is the clinics and hospitals have been equipped with high-tech equipment.

Public health research is scientifically relevant and significant. Many works in domestic and foreign literature are devoted to the analysis of factors affecting public health. There are different approaches to classify them. One approach to the classification of public health factors is based on the origin of the factor relative to the organism of the exposure. Thus, two types of factors are distinguished: endogenous (internal) factors that arise as a result of the development of the human body and exogenous (external) factors that are associated with the environmental effects and do not depend on the person.

The classification based on the nature of factors and the nature of their effects on health is more common in the literature [1-5]. The followers of this classification distinguish the following groups of factors: social and economic (including health conditions) [6-9], environmental and climatic [10], genetic [11], psychological [12] and lifestyle-related factors [13-18]. The specialists in the field of medicine focus on close dependence of public health on the level of health care development and its financing (in domestic and foreign literature) [19-22].

All researchers of the social processes in modern Russia are unanimous in assessing the state of its public health as unfavourable, since the life expectancy is increasing very slowly in the Russian Federation, and healthy life expectancy is decreasing. Over the past seven years, the statistics show population decline, low birth rates and high mortality rates, especially among the men of employable age. There is a high gap in the life expectancy between men and women, every year the general and child morbidity and disability increase. These negative processes are analysed by economists [23, 24], sociologists [25], demographers [26], and doctors [27].

The aim of the research is to analyse the impact of the reforms of the health sector in Russia on public health and other aspects of social life.

\section{Materials and methods}

The article uses general scientific methods of research, such as information and analytical, comparative, systematization methods, methods of qualitative and quantitative analysis. The data from the Federal State Statistics Service of the Russian Federation, the World Health Organization, the World Bank, the Organization for Economic Cooperation and Development, the data from other international organizations and international ratings, the results of analytical researches published in open press are used as an information base.

\section{Results}

Until the early 1990s, the health system in all republics of the USSR was recognized as one of the most reliable (including the World Health Organization (WHO)). Such results were obtained through a close linkage between the processes of health development and social and economic policies of the State, the interaction of authorities and the public aimed at caring for the health of citizens. The Soviet healthcare system was recognized as the most advanced in the world. One of its authors was an outstanding doctor and the first People's Commissar of Health Care of the Russian Socialist Republic, N.A. Semashko. Over the 30 years of his work, he managed to create a unique health care system that had a marked scientific and preventive orientation, a special system of scientific work organization, the state sanitary control and social insurance and used the methods of dispensary and local medical services. He successfully solved the main goals of public health: the timeliness of wide sanitary measures and the accessibility of free and qualified medical and drug care. 
N.A. Semashko put the state efforts to prevent diseases as the basis of public health protection for many years.

In the late 1980s, the crisis of the political and social system, as well as the economic crisis, caused great damage to the Soviet health care system. The decline in public funding that began in the 1970 s by the end of the 1980 s was only $40 \%$ of the required level. Medical equipment was worked out and morally obsolete, the low salaries of medical workers did not give an incentive to work effectively and gradually led to the practice of gifts and donations from the patients. The deficit of necessary drugs gave rise to speculation, and a low quality of medical services, and as the result it led to the distrust of the patients. Thus, by the end of the $1980 \mathrm{~s}$, significant changes were required in Russian health care. Two possible ways of development were identified: the gradual reform of the well-known Soviet system, provided that better experience was preserved and negative phenomena were overcome, or the complete destruction of the Soviet "non-market" system and the creation of a new one based on the decentralization of management, the introduction of compulsory medical insurance and paid services. The leaders of the country chose the second way, while the medical community was not involved in the development of a new health concept.

So, from the beginning of the 1990s, the transition process began in Russia from the socalled "budget-funded" model of health financing (the costs of maintaining a single nationwide network of medical institutions are carried out from the budget) to the "insurance" model (the payment for each medical care service is through the insurance intermediaries - the Compulsory Medical Insurance Fund and private insurance companies). As a result, almost half of the budget began to be spent on the maintenance of health officials (35\% of Federal Compulsory Medical Insurance Fund and 10\% of insurance companies), which are far from the direct provision of medical services. By the way, we note that some developed countries with high indicators of health quality (Sweden, Great Britain, Canada, and others) have effective and developed health system and use "budgetfunded" model of its financing.

As a result, the health care sector has not received full funding for many years. The State has "dropped" down the obligation to provide all citizens of the country with qualitative and accessible medical care, since the main principles of insurance medicine are the decentralization of the medical care system and the strengthening of the economic independence of medical institutions, which have the opportunity to receive funding from an extra-budgetary source through the insurance system.

WHO experts estimate that in order to the public health indicators to be satisfactory, public health funding should be at least $6.6 \%$ of GDP, or $75-80 \%$ of the total health expenses (public and private). According to the Ministry of Health and Medical Industry of the Russian Federation, the maximum shares of state expenses on health care in GDP in the USSR were (in $1960-6.6 \%$, in $1970-6.1 \%$; in $1980-5.0 \%$ ), in Russia in the 1990 s the expenses were less: in $1991-2.6 \%$, in $1994-2.4 \%$. We should note that in the USSR in 1960-1970 the government expenses on health care per capita was approximately at the level of the United States and the developed countries of Europe of those times.

The decline of government funding continued in the Russian Federation at the beginning of the 21 st century: in 2004 it came out at $2.2 \%$ of GDP (it is $75 \%$ of the level of 1991). Only the implementation of the priority national project "Health" causes the increase of the state expenses for health care system (4.2\% of GDP in 2007), however, after 2009 it declines again due to the crisis of the Russian economy and the state budget deficit. So, in 2016, in Russia, \$917.2 was spent from state sources per person, and it is in 5-6 times less than the average one in developed countries (see figure 1). 


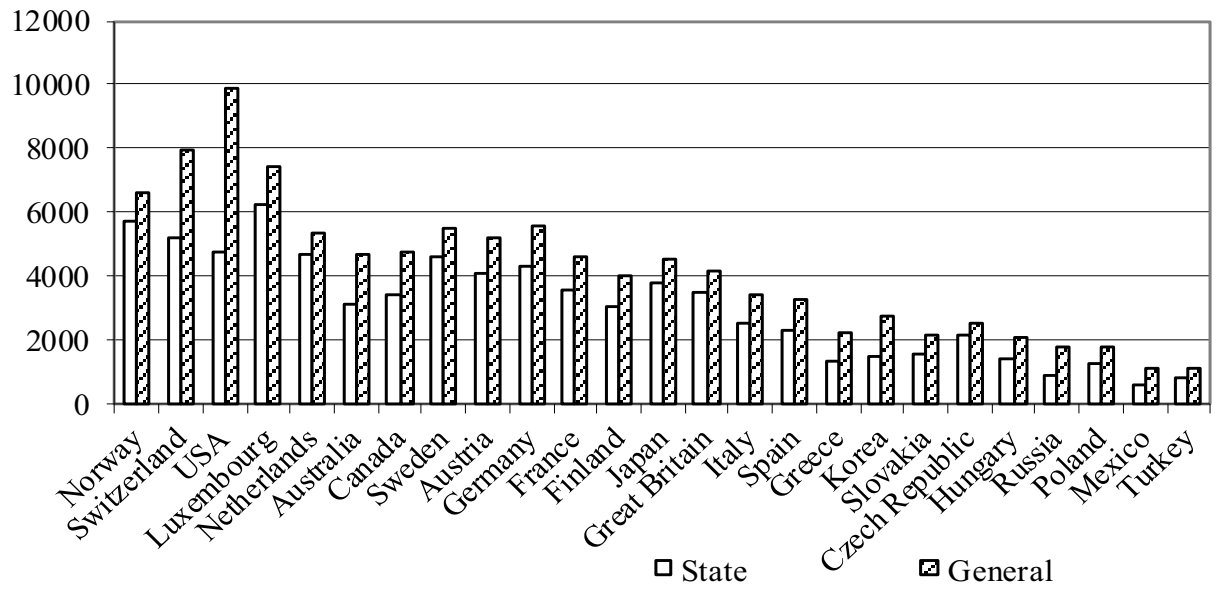

Fig. 1. Health care expenses per capita in 2016 (US \$ PPP). Sources: WHO, World Bank statistics.

Thus, insufficient public and private financing of health care leads to low overall costs in this area [24]. According to the World Bank data, the share of total spending in 2016 in Russia of healthcare system amounted to $7.1 \%$ of GDP, that is 2.4 times less than this share in the United States (17.1\% of GDP), 1.6 times less than in the developed countries of Europe (in France $-11.5 \%$ of GDP) and 1.2 times less than in the countries of Eastern Europe and the Baltic.

Since 2014, the Russian government has begun a new stage of healthcare system reforms, and called it "optimization", as its main goal is to optimize costs by closing inefficient hospitals and expanding the use of high-tech medical institutions.

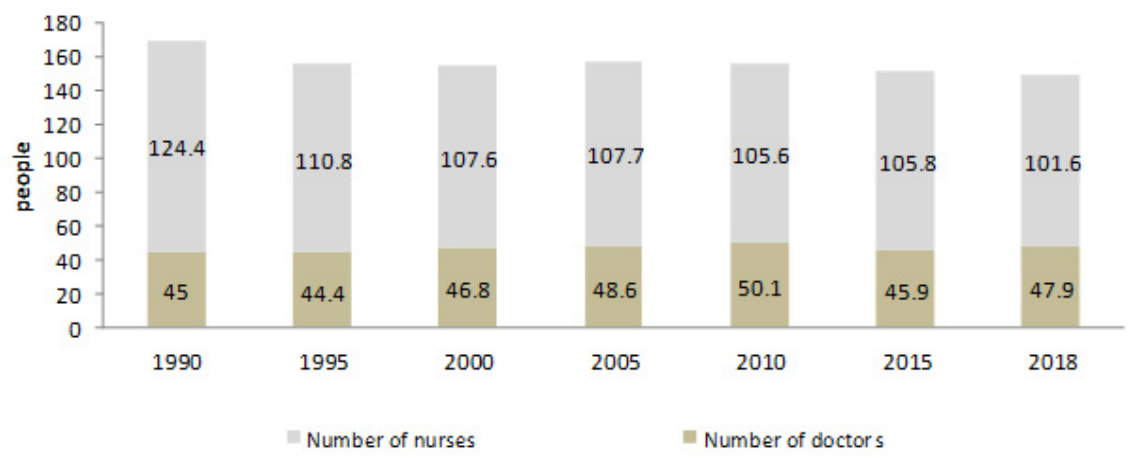

Fig. 2. The number of doctors and nursing personnel in Russia per 10 thousand people). Source: Rosstat data.

The main areas of healthcare system "optimization" are to reduce the number of doctors due to the increase of the medical load; to reduce the number of medical institutions by their enlargement; to increase the salaries of doctors and medical personal by reducing the number of them. The only thing that can be noted as the positive goal of optimization is the increase in the equipment of clinics and hospitals with high-tech equipment. 
One of the arguments of "optimization" is the statement that in Russia there is an excess of doctors and nursing personnel in the healthcare system (see figure 2), although in many developed countries (Switzerland, Germany, Norway, Finland, the USA, Australia, Sweden, and others) there are more doctors and nurses per 1000 people than in Russia (see figure 3).

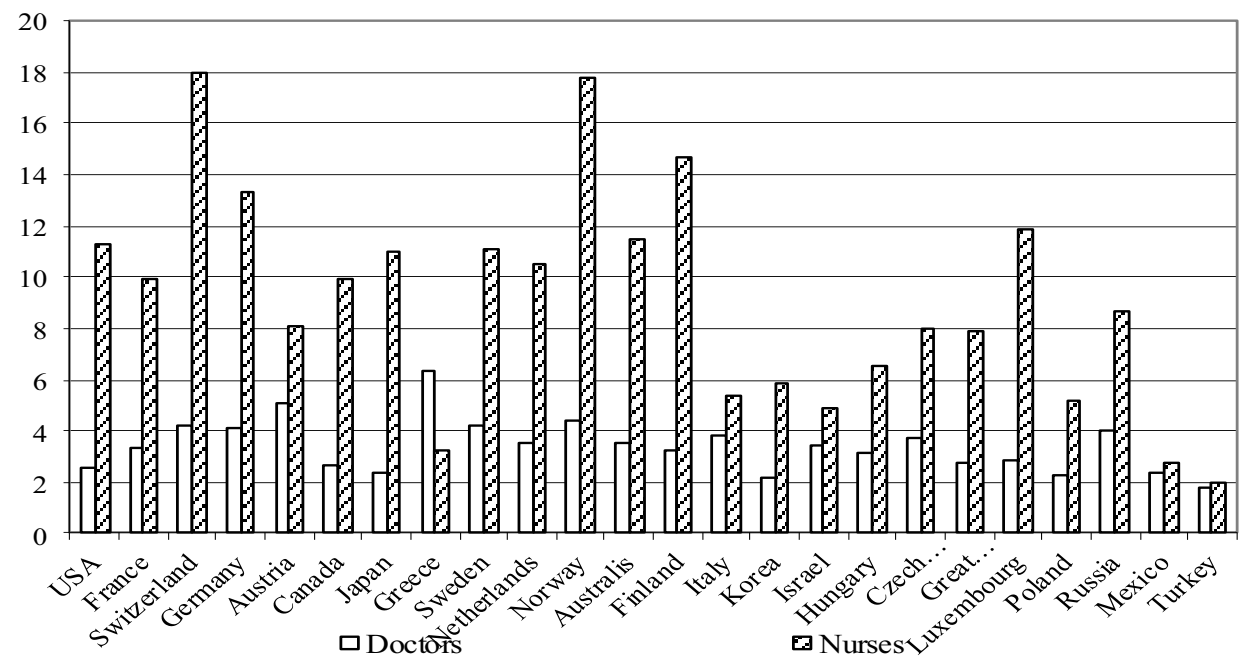

Fig. 3. The number of doctors and nursing personnel in 2015 per 1000 people. Source: Statistics of the Organization for Economic Cooperation and Development (OECD).

The results of the so-called "optimization" in the health care system were summed up by the Accounts Chamber in 2015 [28]: for a year of "optimization" there was a significant reduction in medical personnel, by 90 thousand, and the secondary job increased up to $140 \%$; many hospitals reduced the doctors' load, while the gap between the salaries of the doctors and the heads of medical institutions increased tenfold. The number of hospital beds and medical personal in rural hospitals were significantly reduced, resulting in a significant decrease in the access to health care for rural residents. The load on district doctors over the years of reforms has been increased several times, if earlier the standard was 1,700 people per doctor, now it is up to 3,000 people in some medical institutions.

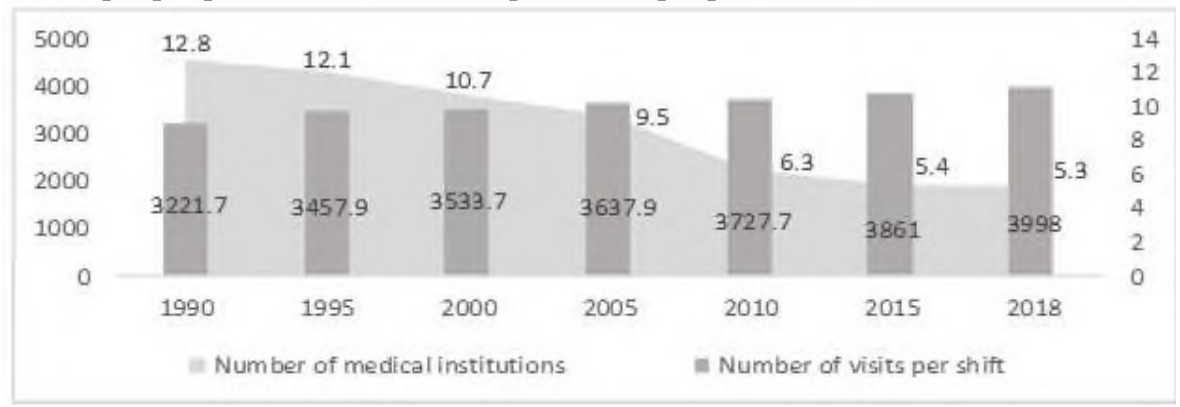

Fig. 4. Number of medical institutions (thousand) and number of visits per shift (thousand) of medical and outpatient clinics in Russia. Sources: data from Rosstat and Russian Legal Information Agency.

As a result of "optimization", the number of hospital institutions was decreased more than twice, but the number of visits per shift increased significantly. If earlier, the number of visitors was limited to the circle of people prescribed in this district, now under the 
health insurance policy any number of citizens can visit any clinic, it led to the increase in the load of doctors per shift by $24 \%$ compared to 1990 (see figure 4 ).

The number of complaints and blames about a significant increase in queues and poor organization of the patient admissions has increased. According to Rosstat, the average number of days waiting for hospital admission has increased twice as large. The number of people who request medical assistance but have not received for various reasons has also increased. The number of refusals in ambulance calls has increased by almost $22 \%$. Against the background of a decrease in the number of hospitalized patients, the number of inhospital fatalities increased from 444.6 thousand people in 2005 to 568 thousand in 2018 (according to the statistical data from 61 regions of the Russian Federation) [28].

\section{Discussion}

Both at the beginning of the reform of the healthcare sector and at present, a lot of complaints have been identified of the work of primary medical institutions. Patients cannot get an appointment with the necessary specialist for a long time; they have to wait for the appointed time for a month, and sometimes more. As a result of the reduction in the number of specialized doctors and the increase in waiting periods for admission, the patients are forced to go to private clinics or pay for an appointment with a doctor in a public medical institution in order to get help faster. State clinics are willing to offer paid services; this is due to the fact that medical institutions need to fill the budget funding deficit. According to the Accounts Chamber, as a result of the reform, there is a "replacement of free medical care by a paid one". According to Rosstat, the volume of paid medical services to the population increased from 2005 to 2017 from 110 billion to 626.6 billion rubles per year.

The replacement of free medical care by a paid one affects the people on lower incomes. It is primarily 48 million of pensioners, whose average pension is 14 thousand rubles. According to academician A.G. Aganbegyan, the average pension of Russian pensioners is 2-4 times lower than that of pensioners of 10 former socialist and developing countries at the same level of social and economic development (table 1). In addition, the incomes of all Russian citizens for the period 2013-2019 decreased by 7.5\%, and the number of the poor increased by 5 million people. Of the 100 leading countries in the world in terms of GDP per capita and real income, Russia ranks approximately 45th (see figure 5), and in terms of the standard of living of pensioners it ranks 78th [29].

Table 1. The size of pensions by countries in 2019 in \% to the Russian pension, taking into account the market exchange rate of the ruble. Sources: compiled by [29].

\begin{tabular}{|c|c|c|c|c|c|c|c|c|c|}
\hline 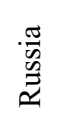 & 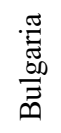 & 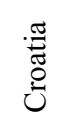 & 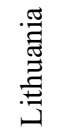 & 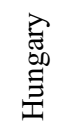 & $\frac{\frac{\pi}{\pi}}{\frac{\pi}{\pi}}$ & $\begin{array}{l}\stackrel{\pi}{\Xi} \\
\stackrel{0}{0} \\
\text { 苟 }\end{array}$ & 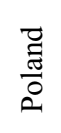 & 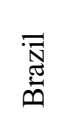 & 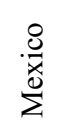 \\
\hline 100 & 142 & 178 & 182 & 196 & 224 & 235 & 241 & 314 & 459 \\
\hline
\end{tabular}

Inflation processes are worsening the situation, which lead to the increase in prices for pharmaceuticals and paid medical services (according to statistics, the index of prices for medical services in 2016 compared to the previous year amounted to $107.8 \%$ with total inflation of $105.4 \%$ ), and the decrease in real incomes of the population (real disposable incomes of the population in 2016 decreased by $13 \%$ compared to 2013). 


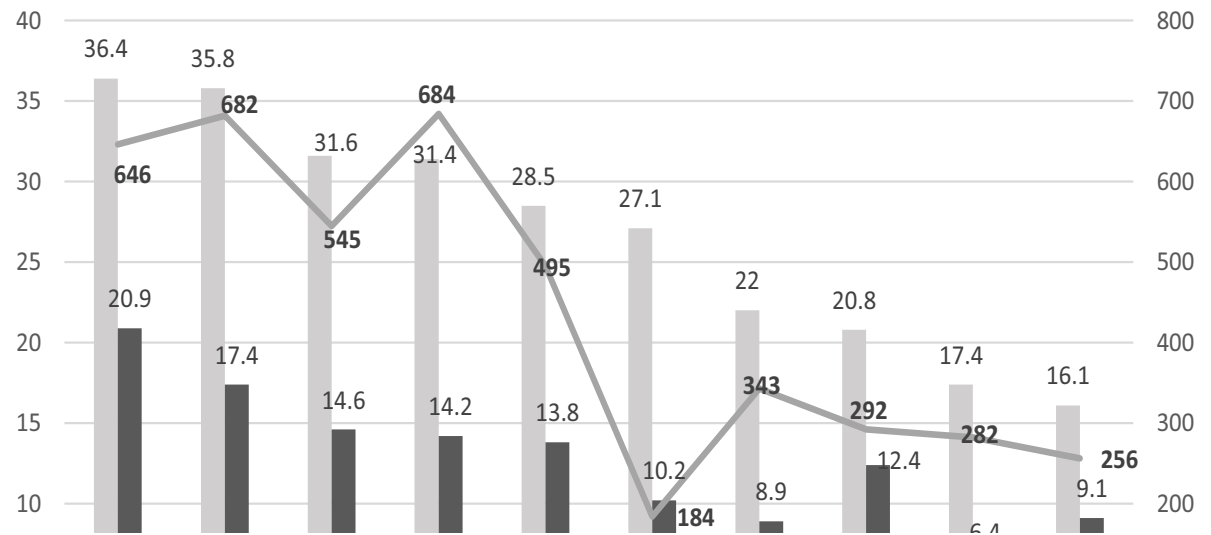

Fig. 5. GDP per capita (thousands of dollars) and minimum wages (dollars) Source: [29].

The expenditure of the population on health services accounts for a significant part of family income, from $10 \%$ to $30 \%$. The researchers state that for most Russians, a further increase in the share of expenses for medical services is impossible, as it reduces the expenses of other vital items of the family budget (most often for high-quality food), and it also worsens health.

The choice of paid medical services by the patients is dictated by the nature of diseases, most often the oncological ones. The growth of them is observed annually: from 2,386.8 thousand people registered at the end of 2005 to 3,762.3 thousand people in 2018. In Russia, the survival rate of patients with cancer is one of the lowest in the world (see figure 6). The average life expectancy of patients suffering from severe chronic diseases in Russia is very small and amounts to 12 years (in the EU countries, it is 18-20 years) [30].

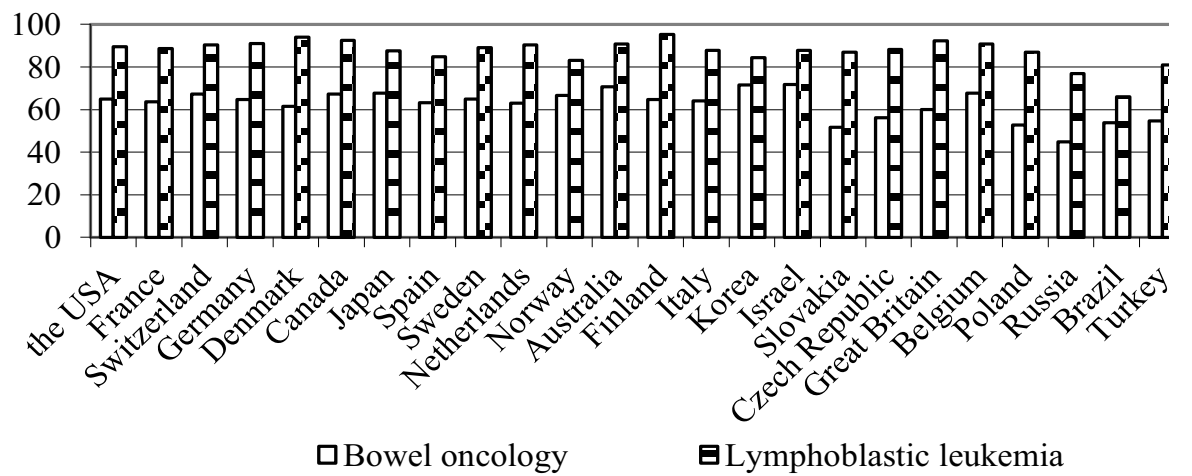

Fig. 6. Survival rate of patients with cancer in 2010-2014 (\% of survivors in the total number of patients). Source: WHO statistics.

As a result of health reforms, medical institutions and health workers are losing patient confidence. According to the surveys of the Higher School of Economics in 2014, 32\% of patients who applied to a medical institution noted a deterioration in the work of hospitals and clinics (among patients with chronic diseases, $41 \%$ of them consider it) [31]. According to Rosstat, in $2018,34.5 \%$ of patients with a need for medical care did not get the appointment with the doctors, explaining the reason as follows: they are not satisfied with the work of the medical organization $(30.2 \%)$, they do not reckon on an effective treatment 
$(21.7 \%)$, there is no time $(23.8 \%)$, the necessary treatment can be obtained only on a paid basis $(14.6 \%)$, it is difficult to get to the medical organization $(4.5 \%)$, they cannot get to the medical organization without assistance $(3.4 \%)$, they are treated by themselves $(51 \%)$. The phenomenon of the modern state of the healthcare sector in Russia is that the population prefers to be treated itself, as the qualifications of the doctors are very low, only about $20 \%$ of diagnoses are initially made correctly, about $60 \%$ of them are needed clarification, and $20 \%$ were completely incorrect. According to the results of Federal Compulsory Medical Insurance Fund inspections, in 2017, various violations are found in $13 \%$ of patient disease cases.

Based on the statistics, we consider how health care reforms have affected public health demographics (table 2).

Table 2. Demographic indicators of public health in Russia (per thousand people). Sources: Rosstat data.

\begin{tabular}{|l|c|c|c|c|c|c|c|}
\hline \multicolumn{1}{|c|}{ Indicators } & 1990 & 1995 & 2000 & 2005 & 2010 & 2015 & 2018 \\
\hline Birth rate & 13.4 & 9.3 & 8.7 & 10.2 & 12.5 & 13.3 & 10.9 \\
\hline Mortality & 11.2 & 15.0 & 15.3 & 16.1 & 14.2 & 13.0 & 12.5 \\
\hline $\begin{array}{l}\text { Infant mortality } \\
\text { (died under 1 year } \\
\text { of age per 1,000 } \\
\text { live births) }\end{array}$ & 17.4 & 18.1 & 15.3 & 11.0 & 7.5 & 6.5 & 5.1 \\
\hline Natural increase & 2.2 & -5.7 & -6.6 & -5.9 & -1.7 & 0.3 & -1.6 \\
\hline Life expectancy & 69.2 & 64.5 & 65.3 & 65.4 & 68.9 & 71.4 & 72.9 \\
\hline
\end{tabular}

Rosstat data indicate that the mortality rate in the Russian Federation remains one of the highest in the world. WHO experts identify the factors that explain the high mortality rates: a low level of medical care, alcohol and tobacco use, lack of exercise, poor nutrition and a poor environmental situation [32].

These factors should include low incomes (economic factor). It is the low level of income that does not allow the population to request paid medical care, maintain a healthy diet, afford a family the rest in a sanatorium or by the sea, and regular exercise.

All these factors can negatively affect the birth rate due to uncertainty about the future. All these lead to negative population growth, especially during an unstable economic situation.

The public policy and the efforts of the country leadership are needed to solve the identified problems. Russia possesses such an experience. For example, stringent administrative measures were required (at the insistence of WHO) to revise health policies to combat the alcohol market and reduce harmful alcohol use. The President of the Russian Federation explicitly recognized the relevance of this problem, linking the shorter life expectancy of the population (compared to Western European countries) with alcohol abuse. As a result of a number of political and economic measures adopted by the government, the total (registered and unaccounted for) alcohol consumption for the period from 2007 to 2016 was reduced by 3.5 liters of pure alcohol per capita, and in the period from 2005 to 2015, the number of new cases of alcoholic psychoses decreased from 52.3 to 20.5 per 100 thousand people. The main thing is the decrease in the death rate due to alcohol consumption, especially among males [32].

It should be said that health care reform has several successful results: from 2012 to 2017, the level of occupational diseases decreased by $23.4 \%$; the rehabilitation beds became 1.7 times more; the infant mortality rates decreased by $35 \%$ and the maternal mortality rates decreased by $23.5 \%$ t; life expectancy at birth was 72.7 years (in 2017), it is an increase of $2.5 \%$ compared to 2013 .

The first stage of the implementation of the new health strategy will be finished by 2021 , by that time it is planned to achieve an increase in the life expectancy up to 74 years 
(by 2025 the life expectancy is planned to increase up to 78 years), from 2012 to 2017 , the infant mortality rates - by $35 \%$, maternal mortality rates - by $23.5 \%$. To achieve the success of the reform, the President set the task to adjust electronic interaction between clinics, pharmacies and citizens in order to simplify and advance patients' access to specialists of various profiles. In addition, the President announced the creation of world-class children rehabilitation centers in Russia, which will have to lay the foundation for the creation of the whole system of such institutions.

It should be noted that the modernization of the healthcare sector has indeed brought the material and technical base of domestic medicine to a new level. The technical equipment of treatment and prevention organizations has improved, many doctors have received new opportunities, which were previously limited to outdated equipment, the number of patients who received high-tech care has increased by 2.3 times, new technologies for the treatment of cardiovascular diseases have been introduced, which has reduced mortality from these causes.

It should be noted that funds have not always been spent effectively and what was needed for. There are cases of idle and obsolescence of new medical equipment due to the lack of qualified personnel who can apply new technologies of examination and treatment in practice. Also, only before the presidential election of 2018, the implementation of the so-called "May decrees" was begun, and the salaries for medical workers were increased, but at the same time the payments for high qualifications and regional allowances could be withdrawn.

Despite the adoption of a number of national health programs, we still observe in Russia a weak health system that is unable to cope with many types of complex diseases, lagging behind the effectiveness of medicine in developed countries. The medical experts say, in order to eliminate this gap, a scientifically sound strategy for the development of health care is needed, which will determine the priority areas of expenditure [33].

In the spring of 2020, the coronavirus epidemic exacerbated the blunders of health care reform. According to the surveys of the Levada Center, by the time of the epidemic, $52 \%$ of Russians have not been satisfied with the state of health care, $48 \%$ have not believed that the Russian medicine will cope with the epidemic. The main arguments are the high cost and inaccessibility of qualitative treatment for citizens, as well as the lack of qualified doctors and modern equipment [34]. Rosstat data show that from the beginning of 2013 to the end of 2019, the number of junior medical staff has decreased by 2.6 times, the nursing personal has decreased by $9.3 \%$, doctors - by $2 \%$, infection disease doctors - by $10 \%$ (compared to 2011), the number of beds at the infectious profile institutions has decreased by almost 2.4 times. But among the successes of Russian medicine there has already been the experience of fighting infections: in 1990 0.35\% of infectious patients died in Russia, and in $2018,0.82 \%$ of them. According to the WHO statistics, in terms of mortality from infections, Russia ranks 87 th in the world.

In connection with the shortage of personnel during the pandemic, the President of the Russian Federation, V. Putin, proposed, if necessary, to involve medical residents, professors, teachers and students into the work. Voluntarily 130 thousand volunteers joined the work. Medical hospitals were rapidly reassigned throughout the country to infectious diseases hospitals and departments; in a short time, military builders built new hospitals in all regions of Russia. For example, if at the beginning of the epidemic in Moscow, infected or suspected coronavirus patients were hospitalized into infectious hospitals No. 1 and No. 2, as well as in a new complex in Kommunarka, then after a short time, they began to be taken by the National Medical and Surgical Center named after N.I. Pirogov, N.V. Sklifosovsky Scientific Research Institute of First Aid, City Clinical Hospital No. 15 named after O.M. Filatov and other medical institutions. All hospitals and departments have adapted the rooms, installed the necessary equipment and trained the personnel. 
The doctors and nurses work for 12 hours, they do not have the opportunity to go home due to the threat of infecting their families, they eat in the hospitals (free lunches and dinners are voluntarily prepared for them and delivered by food entrepreneurs, which is now closed to other consumers), they spend the night in the hotels that provided them with their temporarily empty rooms for free. In most cases, the doctors and the medical personnel show an amazing dedication, professionalism and discipline. Today they are national heroes, and the public is already thinking about how to bring the state's attention to the healthcare sector in a new way in order to rebuild it to the needs and interests of the entire population, and make the profession of a medical worker the most prestigious!

The Government of the Russian Federation financed 10.2 billion rubles to the Ministry of Health for additional payments to medical workers for work on nursing coronavirus patients. The doctors are supposed to be paid 80 thousand rubles to the main earnings per month, nurses - 50 thousand rubles each, paramedics - 25 thousand rubles each. In the event of the death of an employee, his family will be able to receive 2.7 million rubles; in case of disability - 688 thousand rubles, 1.3 million rubles, and 2 million rubles depending on the degree of disability; in the event of infection, which led to the disease, but did not lead to the employee's disability, the employee will be paid 68.8 thousand rubles. Medical workers will be able to receive payments from the Social Insurance Fund. Today, on May 29, 2020, there are 107 medical workers - doctors, nurses and ambulance workers - in the list of those who have been killed by coronavirus in the Russian Federation. This list is maintained by the medical community itself on the Covid-memory website.

At the end of May 2020, the disease attack rate has slowed down. Up to May 31, 2020, the total number of cases in Russia is 406,000 people, the share of deaths is $1.15 \%$, and the share of recovery is $42.36 \%$.

\section{Conclusion}

The pandemic of coronavirus infection, which has acquired an inevitable global character, has revealed the acute problem of our time that is the weakness and imperfection of the health system. It makes us think about the need for its serious and thoughtful reform. The healthcare sector, together with the environmental situation and the level of economic development and well-being of people, is one of the most important factors in maintaining and promoting public health.

Over the past decade, Russia has been actively reforming the healthcare system, but there are many unresolved problems in this area. First of all, there is a discrepancy between the state's obligations to provide free medical care to citizens and the financing allocated to the health sector. The transition to insurance medicine in Russia has not given positive results, but only aggravated the situation with underfunding. In addition, the commercialization of the healthcare sector due to the lack of proper mechanisms for its government regulation will not fully meet the needs for preserving and promoting public health. The issues of social and professional protection of medical workers have also not been resolved. It has led to a low level of medical personnel training and a drop in the prestige of medical professions.

All these facts adversely affect public health, which for several decades has not been able to overcome such negative indicators as high mortality, including infant mortality, low fertility, population decline, a high gap in life expectancy between men and women, low healthy life expectancy, a slow increase in life expectancy at birth, compared with Western countries, increasing general and child morbidity and disability. All these characteristics give public health the status of a threat to national security.

Today, the real life has put an alternative before the state and the community of medical workers: either to strengthen the state role in the management and financing of health care 
and fully ensure the constitutional rights of the citizens to receive guaranteed free medical care, or further reduce the state's obligations to provide free medical care to the population and, as a result, increase the role of private medicine. The first way involves the strengthening of Russia as a state that provides its citizens with social guarantees. The second way also means the further copying of the European model of health system organization, which now, during the period of the coronavirus pandemic, has not demonstrated the best of its characteristics. The developers of the concept of healthcare sector reforms from the Higher School of Economics insist on the second variant [31].

The destiny of Russia as a state, which declares its main goal to ensure security, decent life and free development to every citizen, depends on what choice will be made.

Work is performed under the research work plan of the Institute of Economics and Industrial Engineering of SB RAS, the project XI.170.1.1. "Innovative and environmental aspects of the structural transformation of the Russian economy in the new geopolitical reality", № AAAA-A17$117022250127-8$.

\section{References}

1. J. Santos, K. Yu, S. Pagsuyoin, R. Tan, Time-Varying Disaster Recovery Model for Interdependent Economic Systems Using Hybrid Input-Output and Event Tree Analysis, Economic Systems Research 26, 1, 60-80 (2014)

2. E. Koks, M. Thissen, A Multiregional Impact Assessment Model for disaster analysis, Economic Systems Research 28, 4, 429-449 (2016)

3. F. Nagashima, S. Kagawa, S. Suh, Identifying critical supply chain paths and key sectors for mitigating primary carbonaceous $P_{2}{ }_{5}$ mortality in Asia, Economic Systems Research 29, 1, 105-123 (2017)

4. J. Santos, L. May, A. Haimar, Risk-Based Input-Output Analysis of Influenza Epidemic Consequences on Interdependent Workforce Sectors, Risk Analysis 33, 1620-35 (2013)

5. L. Atuesta, G. Hewings, Economic Welfare Analysis of the Legalization of Drugs, Economic Systems Research 25, 2, 190-211 (2013)

6. N.M. Rimashevskaya, Social policy of saving the people: a radical change in the negative trend in the health of the Russian population, Economic and social changes: facts, trends, forecast 4(12), 48-60 (2010)

7. P. Barlow, Global disparities in health-systems financing: A cross-national analysis of the impact of tariff reductions and state capacity on public health expenditure in 65 low- and middle-income countries, 1996-2015, Health \& Place 63, 57-68 (2020) https://doi org/10 1016/j healthplace 2020102329

8. C. Bohk, R. Rau, Impact of Economic Conditions and Crises on Mortality and its Predictability, Kolner Z Soz Sozpsychol 67(1), 71-294 (2015)

9. T.O.Tagaeva, L.K. Kazantseva, Public Health and Medical Care in Russia: Status and Problems, International Journal of Economic Research 14, 7, 165-177 (2017)

10. B.A. Revich, D.A. Shaposhnikov, The Effects of Particulate and Ozone Pollution on Mortality in Moscow, Air Qual Atmos Health 3, 117-123 (2010)

11. S.A. Boitsov, I.V. Samorodskaya, Factors Affecting Population Mortality, Bulletin of the Russian Academy of Sciences 12 (86), 1089-1097 (2016)

12. A.V. Korolenko, Factors of public health: experience of sociological research (on the materials of the vologda region), Bulletin of Nizhny Novgorod University named after N I Lobachevsky, Series: Social Sciences 1(49), 89-102 (2018) 
13. N. Willanda, M. Nethercoteb, Smoking in apartment buildings - Spatiality, meanings and understandings, Health \& Place 61, 2-8 $\quad$ (2020) https://doi.org/10.1016/j.healthplace.2019.102269

14. D. Mattionia, A. Locontob, G. Brunoria, Healthy diets and the retail food environment: A sociological approach, Health \& Place 61, 9-15 (2020) https://doi org/10.1016/j.healthplace.2019.102244

15. D. Zaridze, S. Lewington, A. Boroda, Alcohol and mortality in Russia: prospective observational study of 151000 adults, Lancet 383, 1465-1473 (2014)

16. F. Wedegaertner, S. Geyer, S. Arnhold-Kerri, Alcohol use disorder-related sick leave and mortality: a cohort study, Addict Sci Clin Pract 30, 1-9 (2013)

17. H. Jayasekara, D.R. English, R. Room, R.J. MacInnis, Alcohol consumption over time and risk of death: a systematic review and meta-analysis, Am J Epidemiol 179, 10491059 (2014)

18. S. Gössling, A. Choi, K. Dekker, The Social Cost of Automobility, Cycling and Walking in the European Union Author links open overlay panel, Ecological Economics 158, 65-74 (2019) https://doi org/10 1016/j.ecolecon 201812.016

19. G. Ulumbekova, Healthcare of Russia: 2018-2024 What to do?, Bulletin of VSHOUZ 1, 9-16 (2018)

20. B. Rudnic, V. Romanova, The Budgetary Financing of Socio-Cultural Sphere, Journal of the New Economic Association, 2 (34), 124-142 (2017)

21. B. Rudnic, Public Funding Mechanisms of Organizations of the Socio-Cultural Sphere, Journal of the New Economic Association 1 (41), 188-194 (2019)

22. B.H. Apouey, Health policies and the relationships between socioeconomic status, access to health care, and health, Isr J Health Policy Res 2, 50 (2013)

23. A.G. Aganbegyan, Demographic drama on the path of perspective development of Russia, Population, 3, 4-23 (2017) DOI: 10 26653/1561-7785-2017-3-1

24. A. Aganbegyan, On Goals and Measures of health Care reform in Russia, Economic issues 2, 149-157 (2014)

25. L. Shilova, Modernization of the Russian health care: challenges, expectations and reality, Bulletin of the Institute of sociology 6, 146-162 (2013)

26. W. Sanderson, S. Scherbov, Faster Increases in Human Life Expectancy Could Lead to Slower Population Aging, PLoS One 15, 6 (2015) URL: http://doi.org/10.1371/journal.pone.0121922 (09.04 2018)

27. S.A. Boitsov, I.V. Samorodskaya, Factors Affecting Population Mortality, Bulletin of the Russian Academy of Sciences, 12 (86), 1089-1097 (2016)

28. S. Fadeichev, The Chamber of Accounts checked the optimization in the sphere of healthcare, culture, education and social services, The Chamber of Accounts (2016) URL: http://www ach.gov.ru/press center/news/21297 (1.06.2016)

29. A. Aganbegyan, The economy is quarantined The main thing now is to compensate for the loss of income of citizens, Arguments and facts 17, 16 (2020) www aif ru

30. D. Beliaev, M. et al., Biosynthesis lipase from the fungus Penicillium hordei isolated from waste fat, E3S Web of Conferences, 164, 06029 (2020) doi: 10.1051/e3sconf/202016406029

31. N.N. Kochkina, M.D. Krassilnikova, S.V. Shishkin, Availability and quality of care in population assessments: preprint WP8/2015/03, National Research Institute "the Higher School of Economics", Moscow Ed House of the Higher School of economics, (Series WP8 "State and Municipal Administration") 
32. World health statistics 2017: monitoring health for the SDGs, Sustainable Development Goals

33. G. Ulumbekova, The relationship of health financing and health indicators for the Russian, Federation Lessons and recommendations for Russia, Health economics 3, 30-34 (2010)

34. Coronavirus pandemic, the Levada Center URL: https://www.levada.ru/2020/03/26/pandemiya-koronavirusa/ (accessed date May 20, 2020) 